Article

\title{
Reasons for and Facilitating Factors of Medical Malpractice Complaints. What Can Be Done to Prevent Them?
}

\author{
Bianca Hanganu ${ }^{1}$, Magdalena Iorga ${ }^{2,3, * \mathbb{D}}$, Iulia-Diana Muraru ${ }^{2}$ and Beatrice Gabriela Ioan ${ }^{1}$ \\ 1 Legal-Medicine Department, Faculty of Medicine, "Grigore T. Popa” University of Medicine and Pharmacy \\ of Iasi, 700115 Iasi, Romania; bianca-hanganu@umfiasi.ro (B.H.); beatrice.ioan@umfiasi.ro (B.G.I.) \\ 2 Behavioral Sciences Department, Faculty of Medicine, “Grigore T. Popa” University of Medicine and \\ Pharmacy Iasi, 700115 Iasi, Romania; diana.muraru@umfiasi.ro \\ 3 Faculty of Psychology and Education Sciences, "Alexandru Ioan Cuza” University of Iasi, \\ 700554 Iasi, Romania \\ * Correspondence: magdalena.iorga@umfiasi.ro
}

Received: 3 May 2020; Accepted: 25 May 2020; Published: 27 May 2020

\begin{abstract}
Background and objectives. Medical malpractice is an increasing phenomenon all over the world, and Romania is not spared. This matter is of concern as it has a significant impact on the physicians and the patients involved, as well as on the health care system and society in general. The purpose of our study was to perform an insight analysis on the reasons for medical malpractice complaints as well as the factors that facilitate the complaints to identify specific ways to prevent them and, implicitly, to improve the medical practice. Materials and Methods. The authors conducted a retrospective study of the medical malpractice complaints registered in the period 2006-2019 at the Commission for monitoring and professional competence for malpractice cases in the region of Moldova, Romania, collecting data on both the patients and the medical professionals involved. Results. The authors analyzed 153 complaints directed against 205 medical professionals and identified 15 categories of reasons for complaints, the most significant being related to the occurrence of complications, and to the doctor-patient interaction (e.g., communication, behavior, informed consent). The most frequently reported medical specialties were obstetrics and gynecology, emergency medicine, general surgery, and orthopedics and traumatology. Emergency medicine was often involved in complaints suggesting an over utilization of this department in our country and the need for health policies, which could divert the large number of patients accessing emergency medicine towards primary care. Conclusions. Regarding the dysfunctions in the doctor-patient relationship frequently claimed by patients, the authors concluded that doctors need special undergraduate training and periodic updating during their practice for them to be able to adequately address the challenges of interacting with their patients.
\end{abstract}

Keywords: medical malpractice; doctor-patient relationship; communication; complications; diagnostic error; preventive measures; retrospective study

\section{Introduction}

The medical practice has been regulated throughout its entire historical evolution by specific legal and ethical norms, which are aimed at carrying out the medical act in optimal conditions, protecting the patients, and sanctioning the doctors who violate the norms of good practice [1]. Medicine and science, in general, enjoy quasi-constant advancements, which bring multiple benefits through their wide applicability [2]. Nonetheless, by increasing public expectations, emphasizing the publicity of patient rights [1,3] and the marketing of medicine [3], the progress in technology places a greater 
burden on the shoulders of the doctors, which often leads patients to have unrealistic expectations and causes them to sanction any mistake or any result that does not coincide with their expectations [4]. This, in turn, leads to tensions in the doctor-patient relationship [2]. Thus, the current medical practice risks being dominated by fear of potential malpractice complaints and their consequences on the medical staff.

The increasing number of medical malpractice complaints represents an alarming reality worldwide, with reports from various health services in Europe, the United States of America, and Australia confirming it [5,6]. Thus, Jena et al. (2011) showed that in the United States of America, $7.4 \%$ of medical professionals are accused of malpractice each year [7]. Likewise, a 2009 study showed that about $4 \%$ of the 108,000 physicians insured by a German insurance company faced a medical malpractice accusation each year [8]. In the United Kingdom, the number of complaints against general practitioners (GP) increased more than two-fold during a period of 5 years, between 2007 and 2012 [6]. In Romania, the malpractice complaints submitted to the court annually increased from 8 in 2008 to 65 in 2017, with a total of 331 in the period 2007-2018, 62 (18.73\%) of these being registered in the eight counties included in our study [9].

The increase in the number of malpractice complaints is a burden for both the doctors and the medical system through their impact on the medical practice, as it can lead to the approach to the medical act in a defensive manner, as well as through the judicial procedure which usually lasts for a long time and involves significant costs for physicians and medical institutions $[2,6]$.

Defensive medicine involves requesting more medical tests, more medical opinions, prescribing more drugs, more referrals to specialized examinations, refusing to perform certain high-risk procedures, or even refusing to assist patients with severe illnesses. These practices are not always for the benefit of the patients; on the contrary, they subject them to unnecessary and sometimes risky interventions, increase the costs of medical care, and decrease the level of satisfaction among physicians [2].

To reduce the negative impact of the judicial process for the resolution of malpractice complaints on doctors and patients, an extrajudicial procedure (e.g., no-fault system, mediation) has been introduced in many countries alongside the judiciary system. This extrajudicial procedure has a number of advantages for both the patient and the doctor and the medical system in general. In out-of-court settlements, complaints are resolved more quickly and efficiently, with lower costs compared to judicial resolution. An out-of-court settlement promotes the disclosure of medical practice incidents, which can increase patients' trust in physicians and can improve the physician-patient relationship, thus being preventive, and increases patient safety by improving the quality of medical care [10-12]. Likewise, resolving the complaints out-of-court decreases the level of psychological stress to which the doctor and the patient are subjected, and the doctor can continue or resume his/her professional activity without fear or pressure resulting from the complaint being made in court or released in the press. These latter aspects are particularly important as after the disclosure of the complaints in the press and the presentation in court, even if the doctor is exonerated, the associated psychological stress could irreversibly damage his/her professional life [12].

In Romania, the out-of-court procedure for resolving medical malpractice complaints was legislated in 2006, when the Commissions on monitoring and professional competence for malpractice cases were created. These Commissions carry out their activity at the level of the Public Health Directorates (PHD) in each county and in Bucharest, and their composition is mixed, covering the activity of physicians, dentists, nurses, midwives, and pharmacists. The working procedure of these commissions provides that patients who consider themselves harmed as a result of the medical act, or their family members (in the case of deceased or incompetent patients), may submit complaints accompanied by documents certifying the harm. The complaints are analyzed with the support of medical experts in the targeted medical specialty to determine whether or not the patients have suffered as a result of malpractice. The medical experts who analyze the complaints belong to various medical specialties and are included in a list available nationwide. They are designated randomly, by drawing lots, and their fee is paid by the plaintiff. To prove an act of malpractice, four criteria must be met cumulatively: (a) the existence 
of a deed produced during a prevention, diagnosis, or treatment activity; (b) the deed is causing patrimonial or non-patrimonial (moral) damage to the patient; (c) the guilt of the medical professional; (d) the causal relationship between the deed and the prejudice [13].

This study aimed to analyze the reasons for the complaints of medical malpractice submitted to the commissions at the PHDs in the region of Moldova, as well as the factors that facilitate the complaints, to identify ways to prevent the complaints and, implicitly, to improve the medical practice. Moldova is a large territory located in the northeast and partially the southeast of Romania, between the Carpathians Mountains and the Prut River, and includes 8 counties out of the total of 41, plus the capital city, Bucharest (Bacau, Botosani, Galati, Iasi, Neamt, Suceava, Vaslui, and Vrancea), with a total surface of about $46,000 \mathrm{~km}^{2}$ and around 4 million people.

To our knowledge, this research is the first of its kind in Romania.

This study is part of a broader doctoral research, which aims to identify methods to prevent the complaints of medical malpractice submitted by patients and to reduce their impact on the medical staff.

\section{Materials and Methods}

\subsection{Data Collection}

The authors conducted a retrospective multi-centric study of malpractice complaints registered in the period 2006-2019 at the Commissions on monitoring and professional competence for malpractice cases in the region of Moldova, which includes 8 counties (Bacau, Botosani, Galati, Iasi, Neamt, Suceava, Vaslui, Vrancea). Data were collected from complaints submitted by patients who were treated in either public $(n=26)$ or private $(n=14)$ medical institutions or their family members and from decisions made by the commissions in each case. The collection, storage, and processing of data were done with respect for the confidentiality of personal data of doctors and plaintiffs.

The collected data concerned, on the one hand, the reasons for the complaints and, on the other hand, the persons who made the complaints (patients or family members) and the doctors who were involved in the respective cases. More specifically, the data regarding the persons who filed the complaints concerned the following aspects: the socio-demographic characteristics of the patients (gender, age, residence area); the existence of multiple pathologies; if the patient died or not; the petitioner who filed the complaint (the patient or their family members); the number of days of hospitalization; the existence of multiple hospitalizations. The data about the doctors concerned: medical specialty, professional degree, and gender.

The analysis of the reasons underlying the complaints led to the identification of 15 categories, depending on the central, essential elements mentioned in the complaints. For identifying the categories of reasons, the authors used an inductive approach. All authors read the reasons as stated by the complainants multiple times, and to ensure rigor, they met several times to analyze them. In this way, the authors identified 15 categories related to aspects of the medical act itself or to the doctor-patient relationship and decided together on the inclusion of each reason in one of the established categories.

\subsection{Ethical Approval}

The research was approved by the Research Ethics Commission of the "Grigore T. Popa" University of Medicine and Pharmacy of Iasi, Romania, No. 16434 / July 30, 2019.

\subsection{Statistical Analysis}

The collected data were analyzed using IBM SPSS Statistics, version 23. Percentages, means, and standard deviations were used for the descriptive analysis. The independent samples $t$-Test was used in the case of variables where there were two independent groups to determine if there were any statistically significant differences between the means of these groups. The Chi-square test was used to test the association between categorical variables. 


\section{Results}

We analyzed 153 complaints directed against 205 medical professionals (physicians, nurses, physiotherapists, and dentists). In 12 cases, the plaintiff also complained about the hospital. Of the people who filed complaints, $82(53.6 \%)$ were male, and $71(46.4 \%)$ were female. Their ages ranged from 0 (new-born) to $90(\mathrm{M}=37.21, \mathrm{SD}=24.38)$; however, the analyzed documents did not specify the age of the plaintiffs in 12 cases. Close to half of the patients were deceased (43.8\%). Most of the plaintiffs live in urban areas (67.3\%), and most of them filed the complaints in Iasi (30.1\%) and Galati $(28.1 \%)$ counties. In more than half of the cases, the plaintiffs were members of the patient's family (in case of deceased or incompetent patients). All the data related to the socio-demographic characteristics of the plaintiffs are presented in Table 1.

Table 1. Socio-demographic characteristics of the plaintiffs.

\begin{tabular}{ccc}
\hline Variables & & $\mathbf{N}(\mathbf{\%})$ \\
\hline Gender & Male & $82(53.6)$ \\
County & Female & $71(46.4)$ \\
& Iasi & $46(30.1)$ \\
& Vaslui & $9(5.9)$ \\
& Botosani & $13(8.5)$ \\
& Suceava & $16(10.5)$ \\
& Galati & $43(28.1)$ \\
& Neamt & $8(5.2)$ \\
Deceased & Bacau & $8(5.2)$ \\
Residence area & Vrancea & $10(6.5)$ \\
& Yes & $67(43.8)$ \\
& Rural & $42(27.5)$ \\
Plaintiff & Urban & $103(67.3)$ \\
& Missing data & $8(5.2)$ \\
Multiple & Patient & $63(41.2)$ \\
hospitalizations & Patient's family & $90(58.8)$ \\
& Yes & $57(37.3)$ \\
New-born & & \\
Age (M \pm SD) & Missing & $8(5.2)$ \\
Hospitalization days $(M \pm S D)$ & Yes & $8(5.2)$ \\
& & $37.21( \pm 24.38)$ \\
& & $14.86( \pm 18.86)$ \\
\hline
\end{tabular}

The medical specialties in which most complaints were found were (1) obstetrics and gynecology, with 24 (15.7\%) claims against 29 physicians (14.14\%), (2) emergency medicine, with 18 (11.8\%) claims against 20 physicians (9.75\%), (3) general surgery with 16 (10.5\%) claims against 20 physicians (9.75\%), and (4) orthopedics and traumatology with 12 (7.8\%) claims involving 19 physicians (9.26\%).

We identified 15 categories of reasons for complaints. Categories, examples of specific reasons for each category and the most involved specialties in each category are shown in Table 2.

Table 2. Categories of reasons.

\begin{tabular}{|c|c|c|c|c|}
\hline Category & $\begin{array}{c}\text { Examples of Reasons Mentioned by Patients and Family } \\
\text { Members in Proxy Position }\end{array}$ & $\begin{array}{l}\text { No of } \\
\text { Cases }\end{array}$ & $\begin{array}{c}\text { No of } \\
\text { Physicians }\end{array}$ & $\begin{array}{l}\text { Most Involved } \\
\text { Specialties* }\end{array}$ \\
\hline \multicolumn{5}{|c|}{ I. Reasons Related to Technical Aspects of the Medical Activity } \\
\hline
\end{tabular}


Table 2. Cont.

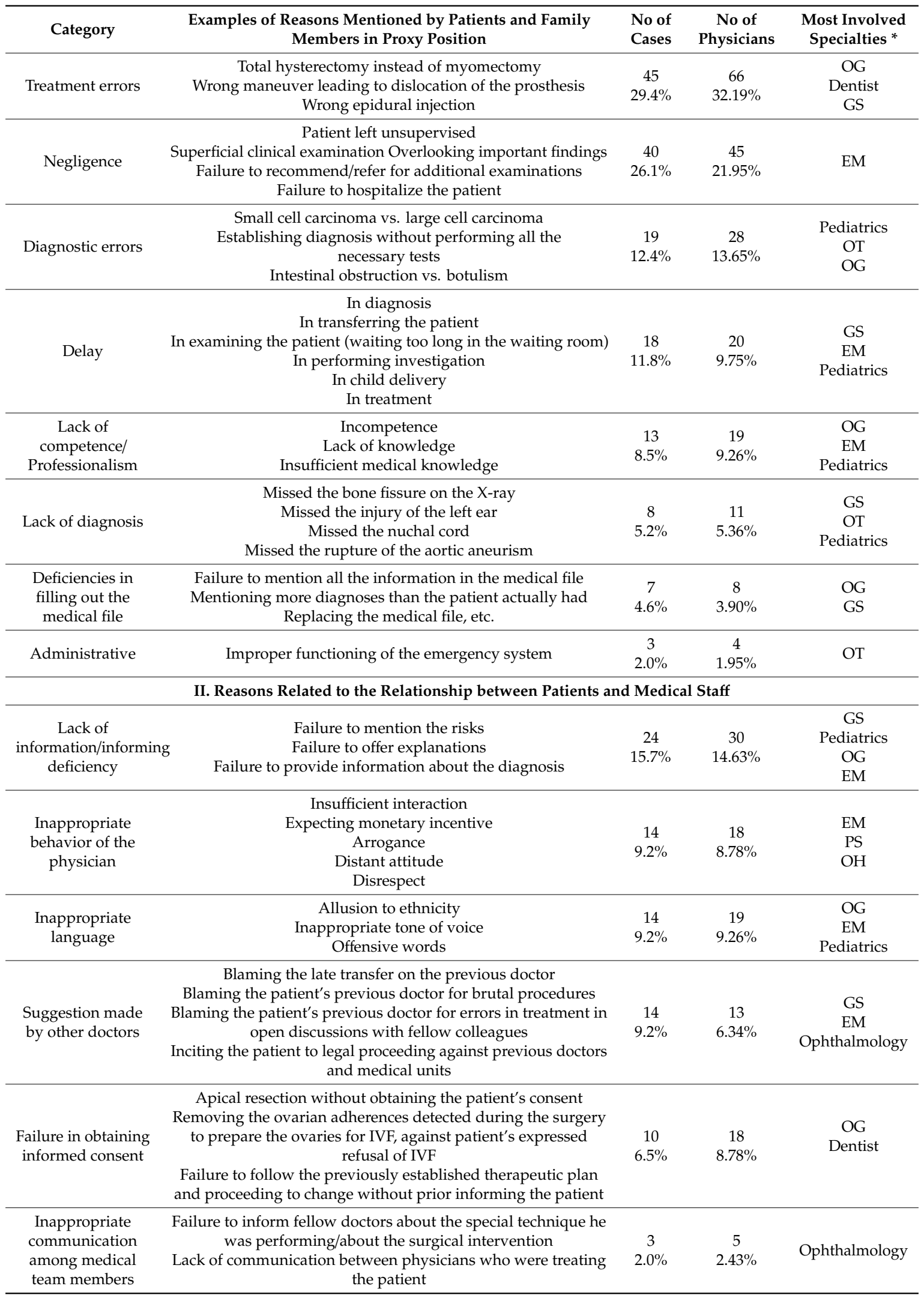

* OG—obstetrics and gynecology, OT-orthopedics and traumatology, GC-general surgery, EM-emergency medicine, PS—plastic surgery, $\mathrm{OH}$-oncology and hematology. 
We tested the association between the reasons mentioned above and some of the study variables concerning the plaintiff (residence area, gender, if the patient was deceased, if the plaintiff was the patient or a family member, if the patient was hospitalized multiple times, if the patient was a new-born) and we found several statistically significant results. Six of the reasons for complaint (treatment errors, reasons suggested by colleagues, inappropriate communication among team members, administrative reasons, legal reasons, and lack of competence/professionalism) were not associated with any of the aforementioned variables. The other nine had associations with the study variables in various ways as showed below.

\subsection{Reasons Related to Technical Aspects of the Medical Activity}

\subsubsection{Complications}

"Complications" as a reason for complaint was associated with:

- Whether the patient was deceased or not: $\chi 2(1)=20.913, p<0.001$; Phi coefficient $=-0.371$, $p<0.001$, indicating a small size effect; more specifically, "complications" was more likely to be a reason for complaint in cases where the patients did not die (54.7\%) compared with the cases where they did $(18.2 \%)$;

- $\quad$ Gender: $\chi^{2}(1)=7.929, p=0.005$; Phi coefficient $=0.228, p=0.005$, indicating a small size effect; more concretely, "complications" was more likely to be a reason for complaint in the cases of female patients $(50.7 \%)$ compared to male patients $(28.4 \%)$;

- Whether the plaintiff was the patient or a family member: $\chi 2(1)=10.402, p=0.001$; Phi coefficient $=-0.262, p=0.001$, indicating a small size effect; in this case, patients were more likely to complain about the occurrence of complications (54.0\%) than their relatives (28.1\%);

- Whether the patient had multiple hospitalizations: $\chi 2(1)=4.370, p=0.037$; Phi coefficient $=0.174$, $p=0.037$, indicating a small size effect; specifically, patients with multiple hospitalizations were more likely to complain about complications (49.1\%) compared to those without multiple hospitalizations (31.8\%).

In addition, there was a statistically significant difference in number of hospitalization days between patients who complained about complications and those who did not: $\mathrm{t}(128)=-4.824$, $p<0.001$; the patients from the former category had a higher mean of hospitalization days $(\mathrm{M}=24.85)$ compared to the latter $(\mathrm{M}=8.71)$.

\subsubsection{Negligence}

"Negligence" as a reason for complaint was associated with whether the plaintiff was the patient or a family member: $\chi 2(1)=4.351, p=0.037$; Phi coefficient $=0.169, p=0.037$, indicating a small size effect. In this case, relatives were more likely to complain about negligence $(32.6 \%)$ than the patient $(17.5 \%)$.

There was a statistically significant difference in number of hospitalization days between patients who complained about negligence and those who did not: $\mathrm{t}(128)=2.900, p=0.004$. Patients who complained about negligence had a higher mean of hospitalization days $(\mathrm{M}=8.94)$ compared to those who did not $(\mathrm{M}=17.12)$.

\subsubsection{Diagnostic Errors}

"Diagnosis errors" as a reason for complaint was associated with whether the patient had multiple hospitalizations: $\chi 2(1)=4.094, p=0.043$; Phi coefficient $=0.168, p=0.043$, indicating a small size effect. Patients with multiple hospitalizations were more likely to complain about diagnosis errors (19.3\%) compared to those without multiple hospitalizations $(8.0 \%)$. 
3.1.4. Delay (in Examination, in Diagnosis, in Treatment)

"Delay" as a reason for complaint was associated with:

- Whether the patient was deceased or not: $\chi 2(1)=13.239, p<0.001$; Phi coefficient $=0.295, p<0.001$, indicating a small size effect; delay was more likely to be a reason for complaint in cases where the patients died (22.7\%) compared to the cases where they did not $(3.5 \%)$;

- Whether the plaintiff was the patient or a family member: $\chi 2(1)=5.166, p=0.023$; Phi coefficient $=0.184, p=0.023$, indicating a small size effect; delay was more likely to be a reason for complaint by family members $(16.9 \%)$ compared to patients $(4.8 \%)$.

\subsubsection{Lack of Diagnosis}

"Lack of diagnosis" as a reason for complaint was associated with gender: $\chi 2(1)=7.402, p=0.007$; Phi coefficient $=-0.221, p=0.007$, indicating a small size effect. More concretely, lack of diagnosis was more likely to be a reason for complaint in the cases of male patients $(9.9 \%)$ compared to female patients $(0.0 \%)$.

\subsection{Reasons Related to the Relationship between Patients and Medical Staff}

\subsubsection{Lack of Information/Informing Deficiency}

"Lack of information/informing deficiency" as a reason for complaint was associated with:

- Whether the plaintiff was the patient or a family member: $\chi 2(1)=7.212, p=0.007$; Phi coefficient $=0.218$, $p=0.007$, indicating a small size effect; lack of information/informing deficiency was more likely to be a reason for complaint for family members $(22.5 \%)$ compared to patients $(6.3 \%)$;

- Whether the patient was deceased or not: $\chi 2(1)=4.223, p=0.040$; Phi coefficient $=0.167, p=0.040$, indicating a small size effect; lack of information/informing deficiency was more likely to be a reason for complaint in cases where the patients died (22.7\%) compared to those cases in which the patients did not die $(10.5 \%)$;

- Whether the patient was newborn or not: $\chi 2(1)=13.857, p<0.001$; Phi coefficient $=0.302$, $p<0.001$, indicating a medium size effect; in cases where patients were newborn, lack of information/informing deficiency was more likely to be a reason for complaint (62.5\%) compared to those in which the patients were not newborn $(13.2 \%)$.

\subsubsection{Inappropriate Language}

"Inappropriate language" as a reason for complaint was associated with whether the patient was newborn or not: $\chi 2(1)=8.082, p=0.004$; Phi coefficient $=0.231, p=0.004$, indicating a small size effect. In cases where patients were newborn, inappropriate language was more likely to be a reason for complaint (37.5\%) compared to those in which the patients were not newborn $(7.6 \%)$.

\subsubsection{Informed Consent}

"Informed consent" as a reason for complaint was associated with whether the patient was newborn or not: $\chi 2(1)=4.662, p=0.031$; Phi coefficient $=0.175, p=0.031$, indicating a small size effect. In cases where the patients were newborn, informed consent was more likely to be a reason for complaint $(25.0 \%)$ compared to those in which the patients were not newborn $(5.6 \%)$.

\subsubsection{Inappropriate Behavior}

"Inappropriate behavior" as a reason for complaint was associated with the residence area (rural or urban): $\chi 2(1)=4.296, p=0.038$; Phi coefficient $=0.172, p=0.038$, indicating a small effect size. In cases where patients lived in rural areas, inappropriate behavior was more likely to be a reason for complaint $(16.7 \%)$ compared to those who lived in urban areas $(5.8 \%)$. 


\section{Discussion}

This study allowed the analysis of data gathered during 14 years of activity of the Commissions on monitoring and professional competence for cases of malpractice in the Moldova region of Romania. Our results showed several findings that could be the starting point for formulating prevention methods designed to the reduction in the number of malpractice claims.

Our study showed that the ground for complaints are both reasons related to technical aspects of the medical activity and reasons related to the relationship between patients and medical staff, these results are consistent with literature data [14]. The analysis of these reasons is important so as to improve the medical practice by identifying various prevention methods that target both the medical practice and the doctor-patient relationship, to improve medical services provided to patients, and to protect the medical staff from complaints [2].

In our study we found that over half of the complaints were registered in two counties (Iasi and Galati). The large number of cases in these two counties (compared to the other counties included in the research) is due, most likely, to the fact that Iasi and Galati are university centers, with clinical hospitals, which can provide a higher level of medical services and can treat more severe cases, and where many patients from other counties in Moldova are referred from smaller hospitals. Likewise, many patients request on their own initiative a referral by the general practitioners to specialists working in university centers, sometimes contrary to their recommendation [15].

Literature data show that there are no medical specialties spared by malpractice complaints, but some specialties have a higher risk compared to others [16].

In our study, the most frequently reported medical specialties are obstetrics and gynecology, emergency medicine, general surgery, and orthopedics and traumatology. These results are partly consistent with those of other studies. Obstetrics and gynecology, general surgery, and orthopedics and traumatology also occupy the first places in studies conducted in other countries, such as the United Kingdom, China or the United States of America [4,7,17].

The increased risk of certain medical specialties for malpractice claims is mainly due to the particularities of the medical services provided and the patients treated. Physicians in obstetrics and gynecology, for example, treat not only one patient, but often at least two (mother and child) or even three, if we take into account the concerns of the future father, while by taking care of the reproductive system of the woman, it also deals with potential future patients, the reproduction of the human species, thus becoming a specialty of the entire family [4]. Patients accessing obstetrics and gynecology services often expect for more than what a doctor can actually do, asking for flawless results of the medical interventions, such as safe labor when the child is to be given birth [18]. Becoming a parent can be an overwhelming issue, and the perinatal period is characterized by plenty of emotions related to the health status of the newborn. As such, this emotional burden on the parents may become a trigger for complaints against professionals in this field when the newborn is not healthy [19].

Physicians in orthopedics and traumatology are at high risk because they have to take care of patients' work capacity [4], which may have significant social and professional implications.

The increased risk for complaints of malpractice in surgical specialties is underlined by Jena et al. (2011), who showed that allegations of medical malpractice occur quite frequently in this specialty. Those authors found that $88 \%$ of physicians in at-risk surgical specialties (neurosurgery, thoracic and cardiovascular surgery, general surgery) had one complaint against them until the age of 45 , and the number increased to $99 \%$ by the age of 65 [7]. Patients who need surgery usually suffer from severe diseases for which they expect doctors to work miracles. As the medical procedures are more complex, the associated risks increase in a directly proportional manner [4].

A peculiar result of our study was the fact that emergency medicine was the second most claimed specialty in terms of the number of complaints, and the third most claimed specialty in terms of the number of doctors involved, which is in contradiction with other studies that found a small number of complaints against the medical personnel who work in emergency medicine units, patients and the general public taking into account that physicians in this specialty work in critical 
conditions [20]. However, a similar result was reported in the study conducted by Hwang et al. (2018) in Taiwan, where this specialty occupied the third place, with $8.5 \%$ of complaints, after obstetrics and orthopedics [18]. Furthermore, unlike various studies published in the literature in which there is an increased number of complaints against general practitioners [21-23], in our study family medicine (which in Romania is equivalent to general practice) was involved in only one complaint against doctors from several specialties.

Our finding that the ratio between the number of complaints in Emergency Medicine and that in family medicine was reversed compared to other studies finds its explanation in the fact that Romanian patients use emergency medicine unit services excessively, to the detriment of primary health care services $[15,24]$. Patients often shunt the family doctors, abusively calling emergency medical services, even in non-life-threatening situations. This overuse of emergency medicine to the detriment of family medicine (which is underused) is also demonstrated by the fact that many ambulance requests, especially during regular working hours, are resolved at the patients' homes, representing situations that could have been solved by the family doctor [15]. An essential reason for patients requesting excessive consultations from emergency services is the possibility to be seen by a doctor without a referral from the family medicine physician or in case they do not have health insurance. Although health insurance is mandatory for all Romanian citizens, European Commission reports show that in 2017, 11\% of the population did not have it [25]. There are certain diseases (e.g., genetic diseases, diabetes, tuberculosis, myasthenia gravis, increased obstetrical risk in pregnant women, peptic ulcer, mental illnesses) $[15,26]$ which can be assessed or followed up by a specialist physician directly in the outpatient department, without a referral from the family doctor [24], which could further explain the lower number of complaints to the latter, by the lower addressability. Moreover, the primary health care system in Romania is not accessible to everyone, about $2.5 \%$ of the population do not have access to a family doctor [27].

In our study, $9.2 \%$ of the patients complained about the doctors' inappropriate language, $9.2 \%$ complained about their inappropriate behavior, and 15.7\% complained about the lack of information or the deficiency in offering information. These issues raise an alarm about how doctors approach and relate to their patients and the fact that deficiencies in the doctor-patient relationship can lead to a malpractice complaint.

Our study highlights that individuals from rural areas were more likely to report inappropriate behavior compared to those from urban areas. In rural areas, the relationship between the doctors and their patients is much closer [28,29]. This closer relationship might result in the patient preferring to wait a long time (sometimes even a few hours) to be examined by their own doctor when the latter is very busy, or even to postpone a consultation if their doctor is not available, instead of contacting another physician [28]. Interpersonal relationships are generally closer in rural areas, where communities are small, people communicate more with each other (for example, they usually all greet even if they do not know each other), they live in communion. The rural environment is characterized by greater social integration, with friendly and neighborly support and involvement by the community, compared to the urban environment [30]. The rural patient, accustomed to close interpersonal relationships in their area of residence, both with the community and with the physician, is disturbed when urban physicians, with less time allocated to patients, interact less with the patient, behave more distantly and sometimes arrogantly, as some patients in our study pointed out. These issues become more relevant when the outcome of the medical intervention is not in line with the patient's expectations.

Data from the literature show that in addition to the actual harm caused to the patient, as an independent reason, an important role in formulating the complaint has a series of triggers, especially related to the relationship between doctor and patient [31], to how the patient is approached by the doctor [5], and to the fact that the doctor often leaves the patient without explanations as to the reasons for the failure of the medical act [32]. At the same time, there are studies showing that despite the occurrence of harm to the patient, the proper way in which physicians have related to their patients contributed to the patients' decision to not complain about the medical act [33]. 
The ability of inter-human relationships, in the form of communication and the attitude of the doctor towards the patient [5], strongly influences the medical practice. Communication failure often predisposes the occurrence of adverse events [34]. Moreover, patients are more likely to complain about the doctor after the occurrence of an adverse event if the doctor-patient relationship is dysfunctional [3]. Thus, the study conducted by Veerman et al. (2019) showed that at least $10 \%$ of patients were disappointed in how their doctors behaved and communicated with them, in the sense that their problems were not given due consideration and that their doctors were too busy to discuss with them [5].

A study conducted in the United States of America that analyzed the malpractice complaints in general surgery showed that $34 \%$ of complaints were related to poor communication [35].

Doctor-patient communication triggers complaints of malpractice also from the perspective of obtaining the medical history. Failure to obtain an accurate medical history predisposes to misdiagnosis and treatment errors, which generates patient dissatisfaction and subsequent malpractice complaint [36]. On the other hand, a good communication may prevent the patient from making a malpractice complaint even if the result of the medical act is not as expected, because the level of communication between doctor and patient allows the latter to understand the situation and accept the result [37]. Regarding the starting point of conflicts, both family members and physicians recognize the implications of poor communication [38]. Doctors who disregard their patients' feelings and concerns, who provide little information, who do not have the patience to listen to or are not open with their patients are more likely to be reported, compared to their colleagues who communicate more efficiently with patients [3].

Our study showed that the lack or deficiency in communication was more likely to be reported by the family than by the patient, rather when the patient had died and when the patient was a newborn. These elements suggest the need of the family to be informed in difficult moments, such as the unexpected death of a family member or the health condition of their children. Moreover, when death occurs in a child, the need for the parents to receive information and explanations is even higher, given that usually a child is not supposed to die from natural causes [20]. Communicating bad news can be a difficult task for doctors, with a great emotional load on both sides. To provide it in an appropriate way, the doctors need specific training and protocols [39]. In general, the perinatal period is associated with a strong emotional load [19], and as the reality of a newborn's health problem adds significant a degree of vulnerability [40], it can strongly upset the new parents, some of them perhaps experiencing parenthood for the first time. Therefore, the need for realistic, accurate information about the medical situation becomes essential $[38,40]$. Moreover, it is necessary that the doctor-parent interaction be grounded on clear, prompt, and compassionate communication by doctors $[38,40]$.

In our study, inadequate informed consent or lack thereof was reported in $6.5 \%$ of cases. This result is closely related to the results of other studies, such as one conducted in Australia, which showed that $5 \%$ of negligence claims and conciliated complaints were related to the process of obtaining the informed consent [32]. Obtaining the informed consent is an important part of the process of communicating with the patient. Agarwal et al. (2018) identified aspects related to professionalism and inadequate informed consent as factors favoring the initiation of malpractice complaints in cases involving spine surgery [41].

Our results showed a higher probability of complaining about the lack of consent in cases where patients were newborns. This result was related to another result of our study indicating that the lack or deficiency of communication was a more common reason for complaint by the patient's family (when the patient died, or the patient was a newborn or incompetent). Data from the literature indicate the need for a family-centered approach in the medical settings for the care of newborns, requiring the adequate approach of the parents [40,42,43]. In a family-centered approach, the parents and the doctor form a partnership in which the parents are offered the opportunity to actively participate in the care of their child [42,43]. Sarin and Maria (2019) reported that parents often show distress, frustration, and alienation when they are not involved in caring for their own child [42], thus creating the premises for complaints when the evolution of the case is not favorable. 
Patients who complain about their doctors for the damage they suffered as a result of a misdiagnosis or treatment error [2] may want to obtain compensation, to find out what happened [3], to get an explanation, or they may want the doctor to admit their mistake [3,31] and express their regret [31]. Patients may also want to prevent the occurrence of similar incidents in the future or for justice to be done, i.e., those responsible for the mistake to be held accountable [3,44].

Our results showed that in 59 (38.5\%) cases the reason for complaints was the occurrence of a complication of the medical act, the complaints being directed towards 75 (36.58\%) physicians. The most frequently claimed specialties for this reason were obstetrics and gynecology (15 complaints, 19 doctors), general surgery (6 complaints, 10 doctors) and orthopedics and traumatology (7 complaints, 9 doctors), all of them major surgical specialties, which, by their nature, involve an intrinsic risk of the occurrence of additional harm during surgical interventions which are often complex [4]. Some of the complications are related to the complexity of the disease, but others are related to errors that could have been prevented [45]. Our results show that women were more likely to claim complications than men and for the complaint to be made by the patients rather than their relatives, probably because the patient is the one who endures the physical suffering associated with the occurrence of a complication and the subsequent necessary treatments. The complaint for the occurrence of a complication of the medical act was associated with a greater number of hospitalization days and with multiple hospitalizations because the occurrence of a complication requires additional medical or surgical treatment.

The diagnostic error was a reason for complaint identified in 19 (12.4\%) cases, involving a number of $28(13.65 \%)$ individual physicians, the three most involved specializations for this reason being pediatrics (4 complaints, 6 doctors), obstetrics and gynecology ( 2 complaints, 3 doctors), and orthopedics and traumatology ( 2 complaints, 5 doctors). This was a more likely reason for complaint for patients with multiple hospitalizations. The lack of diagnosis was a reason for complaint in $8(5.22 \%)$ cases, involving $11(5.36 \%)$ doctors, the most involved specialty for this reason being general surgery ( 2 complaints, 4 physicians). Although the literature data most often refer to diagnosis errors in general (lack of diagnosis, misdiagnosis, and delay in diagnosis), the results of our study showed a lower percentage compared to those reported in other studies. For example, $32.1 \%$ complaints related to diagnosis were reported by Gupta et al. (2018), 38.8\% of them concerning hospitalized patients [46]. Gupta et al. (2018) observed a decrease in this percentage during the 13 years of the study period (January 1, 1999-December 31, 2011), an aspect that can be explained by the increasing accessibility of the diagnosis techniques, especially in the medical imaging field [46]. The diagnostic errors in outpatients were estimated at $5.1 \%$ of the cases [46]. Schaffer et al. (2017) showed that diagnostic errors were the most reported reason in cases of paid claims, being found in $31.8 \%$ of these cases [47]. Diagnostic errors were the most common cause of complaint in the study performed by Saber Tehrani et al. (2013), which showed that diagnostic errors were accompanied by the highest costs and the highest degree of danger for patients [48].

Misdiagnosis is often associated with mistreatment and may require multiple re-admissions in the hospital, increasing morbidity and the associated costs [46]. Agarwal et al. (2018) found 31.6\% claims for delayed diagnosis and $32.7 \%$ claims for failure to provide appropriate treatment, which may underline that acute patients need prompt and appropriate care [41].

In our study the lack of diagnosis was reported by men rather than women, a similar result being obtained by Gupta et al. (2018) [46]. According to the empathizing-systemizing theory, proposed by Baron-Cohen and cited by Zaidi (2010), men tend to systematize, seek solutions, understand, and build different systems, going to the root of the problems, so that everything becomes clear to them. Therefore, male patients are dissatisfied by the lack of a clear explanation for their health problems and start their own search for solutions or answers [49].

The consequences of diagnosis errors have been analyzed by several studies. For example, Zwaan et al. (2010) identified a 6.5\% death rate in a hospital due to adverse events [50]. Gupta et al. (2018) showed that diagnosis errors result in $47.4 \%$ of deaths and $33.9 \%$ of disabilities [46]. In our 
study, diagnosis errors were not significantly associated with the patient's death, this being reported only in $10.6 \%(n=7)$ of the deceased patients. A reason for complaint strongly associated with the patient's death in our study was the delay of the medical act. The most involved specialties for claiming delay in the medical act were general surgery ( 4 complaints, 5 physicians) and emergency medicine (4 complaints, 4 physicians). Delay as a reason for medical malpractice claim in emergency medicine is again associated with the overutilization of the emergency services where the waiting time to receive medical care is inversely proportional to the severity of the emergency.

In cases when the patient is deceased or incompetent (i.e., by age, by physical or psychical disability), the complaint is submitted by a family member. In our study, this occurred in more than half of the cases (i.e., 58.8\%). This aspect has multiple facets. Except for the already mentioned reason regarding the stress and emotions surrounding the perinatal period, the parents of an injured child might be preoccupied by the future of their offspring in case of disability [19]. Likewise, the death of a loved one may cause a great deal of distress, with material or moral prejudice, the family thus being entitled to ask for explanation and compensation in case of the physician's malpractice leading to the misfortunate event [1]

\section{Strengths and Limitations}

This study has several strengths and limitations. Regarding the strengths, this study is the first of its kind to be conducted in Romania and covered a significant geographic part of the country, Moldova being one of the largest Romanian regions. Therefore, the results offer an image of the situation for about $20 \%$ of the country's entire population and can represent the starting point for studies in the other regions, to have a national perspective on this subject. Second, the research analyzed complaints registered for 14 years, offering an objective data analysis. Third, the results are discussed and explained in opposition with other medical systems showing the most vulnerable medical specialties in Romania compared to other countries.

The limitation of the study stems from the fact that some of the cases had missing data regarding the socio-demographic characteristics of the plaintiffs and some of the claims did not contain precise information on the number of doctors involved. This limitation was the result of the fact that the patients gave a personal account of the events, instead of having access to a default form with specific items for each category of information.

\section{Conclusions}

Complaints of medical malpractice continue to follow an ascending trend worldwide, and their consequences are multifaceted, affecting both the medical staff and patients and society in general. Therefore, it becomes significantly necessary to identify solutions meant to reduce the number of complaints, a goal that could be met by conducting studies aimed at formulating recommendations in this regard.

The results of our study showed that the most frequently involved specialties were obstetrics and gynecology, emergency medicine, general surgery, and orthopedics and traumatology. Particularly in this list was the presence of the emergency medicine, a result explained by the overuse of these services in our country and the underutilization of primary health care services. Therefore, health policies are needed to divert the large number of patients accessing emergency medicine to primary care.

Many of the aspects the plaintiffs complained about were represented by deficiencies in the interaction between doctor and patient or his/her family (lack of or deficiency in information, the doctor's inappropriate behavior or language, failure to obtain informed consent). Based on this finding, we consider that doctors need special training during their undergraduate medical studies, as well as periodic updating during their career to meet the challenges of communication and relationships with patients and their families.

Author Contributions: All authors had equal contributions. Conceptualization, B.H. and B.G.I.; methodology, B.H., B.G.I., and M.I.; software, I.-D.M. and B.H.; validation, B.H., B.G.I., and M.I.; formal analysis, I.-D.M. and 
B.H.; investigation, B.H. and B.G.I.; resources, B.H., B.G.I., M.I., and I.-D.M.; data curation, B.H. and B.G.I.; writing—original draft preparation, B.H.; writing—review and editing, B.H., B.G.I., M.I., and I.-D.M.; supervision, B.G.I. and M.I.; project administration, B.G.I. All authors have read and agreed to the published version of the manuscript.

Funding: This research received no external funding.

Conflicts of Interest: The authors declare no conflict of interest.

\section{References}

1. Ioan, B.G.; Nanu, A.C.; Rotariu, I. Răspunderea Profesională în Practica Medicală; Junimea: Iasi, Romania, 2017. (In Romanian)

2. Dolz-Guerri, F.; Gomez-Duran, E.L.; Martinez-Palmer, A.; Castilla Cespedes, M.; Arimany-Manso, J. Clinical safety and professional liability claims in Ophthalmology. Arch. Soc. Esp. Oftalmol. 2017, 92, 528-534. [CrossRef] [PubMed]

3. Chiu, Y.C. What drives patients to sue doctors? The role of cultural factors in the pursuit of malpractice claims in Taiwan. Soc. Sci. Med. 2010, 71, 702-707. [CrossRef]

4. Li, H.; Wu, X.; Sun, T.; Li, L.; Zhao, X.; Liu, X.; Gao, L.; Sun, Q.; Zhang, Z.; Fan, L. Claims, liabilities, injuries and compensation payments of medical malpractice litigation cases in China from 1998 to 2011. BMC Health Serv. Res. 2014, 14, 390. [CrossRef]

5. Veerman, M.M.; van der Woude, L.A.; Tellier, M.A.; Legemaate, J.; Scheltinga, M.R.; Stassen, L.P.S.; Leclercq, W.K.G. A decade of litigation regarding surgical informed consent in the Netherlands. Patient Educ. Couns. 2019, 102, 340-345. [CrossRef] [PubMed]

6. Bourne, T.; Vanderhaegen, J.; Vranken, R.; Wynants, L.; De Cock, B.; Peters, M.; Timmerman, D.; Van Calster, B.; Jalmbrant, M.; Van Audenhove, C. Doctors' experiences and their perception of the most stressful aspects of complaints processes in the UK: An analysis of qualitative survey data. BMJ Open 2016, 6, e011711. [CrossRef] [PubMed]

7. Jena, A.B.; Seabury, S.; Lakdawalla, D.; Chandra, A. Malpractice risk according to physician specialty. N. Engl. J. Med. 2011, 365, 629-636. [CrossRef]

8. Gao, P.; Li, X.; Zhao, Z.; Zhang, N.; Ma, K.; Li, L. Diagnostic errors in fatal medical malpractice cases in Shanghai, China: 1990-2015. Diagn. Pathol. 2019, 14, 8. [CrossRef]

9. Dumitrescu, R.M. Litigious side of the medical malpractice in Romania. Mod. Med. 2019, 26, $197-211$. [CrossRef]

10. Essinger, K. Medical liability alternative ways to court procedures. In Proceedings of the European Conference "The Ever-Growing Challenge of Medical Liability: National and European Responses", Strasbourg, France, 2-3 June 2008.

11. Watson, K.; Koltenhagen, R. Patients' right, medical error and harmonization of compensation mechanisms in Europe. Eur. J. Health Law 2018, 25, 1-23. [CrossRef]

12. Lee, D.W.H.; Lai, P.B.S. The practice of mediation to resolve clinical, bioethical, and medical malpractice disputes. HongKong Med. J. 2015, 21, 560-564. [CrossRef]

13. Legea nr. 95/2006 privind reforma în domeniul sănătăţii, publicată în Monitorul Oficial al României, Partea I, nr. 372 din 28 aprilie 2006, In Romanian. [Law no 95/2006 on healthcare reform, published in the Official Gazette of Romania, Part One, No 372/April, 28th, 2006].

14. Charles, S.C.; Gibbons, R.D.; Frisch, P.R.; Pyskoty, C.E.; Hedeker, D.; Singha, N.K. Predicting risk for medical malpractice claims using quality-of-care characteristics. West. J. Med. 1992, 157, 433-439. [PubMed]

15. Vlãdescu, C.; Scîntee, S.G.; Olsavszky, V.; Hernández-Quevedo, C.; Sagan, A. Romania: Health system review. Health Syst. Transit. 2016, 18, 1-170. [PubMed]

16. Ferrara, S.D.; Baccino, E.; Bajanowski, T.; Boscolo-Berto, R.; Castellano, M.; De Angel, R.; Pauliukevičius, A.; Ricci, P.; Vanezis, P.; Vieira, D.N.; et al. Malpractice and medical liability. European Guidelines on Methods of ascertainment and criteria of evaluation. Int. J. Legal. Med. 2013, 127, 545-557. [CrossRef] [PubMed]

17. Bark, P.; Vincent, C.; Olivieri, L.; Jones, A. Impact of litigation on senior clinicians: Implications for risk management. Qual. Health Care 1997, 6, 7-13. [CrossRef] [PubMed]

18. Hwang, C.Y.; Wu, C.H.; Cheng, F.C.; Yen, Y.L.; Wu, K.H. A 12 year analysis of closed medical malpractice claims of the Taiwan civil court. Medicine 2018, 97, 237. [CrossRef] 
19. Domino, J.; McGovern, C.; Chang, K.W.C.; Carlozzi, N.E.; Yang, L. Lack of physician-patient communication as a key factor associated with malpractice litigation in neonatal brachial plexus palsy. J. Neurosurg. Pediatrics 2014, 13, 238-242. [CrossRef]

20. Casali, M.B.; Mobilia, F.; Del Sordo, S.; Blandino, A.; Genoveze, U. The medical malpractice in Milan-Italy. A retrospective survey on 14 years of judicial autopsies. Forensic. Sci. Int. 2014, 242, 38-43. [CrossRef]

21. Studdert, D.M.; Bismark, M.M.; Mello, M.M.; Singh, H.; Spittal, M.J. Prevalence and characteristics of physicians prone to malpractice claims. N. Engl. J. Med. 2016, 374, 354-362. [CrossRef]

22. Cunningham, W.; Crump, R.; Tomlin, A. The characteristics of doctors receiving medical complaints: A cross-sectional survey of doctors in New Zealand. N. Z. Med. J. 2003, 116, U625.

23. Wallace, E.; Lowry, J.; Smith, S.M.; Fahey, T. The epidemiology of malpractice claims in primary care: A systematic review. BMJ Open 2013, 3, e002929. [CrossRef]

24. OECD/European Observatory on Health Systems and Policies. State of Health in the EU. Romania: Profilul Sănătătii în 2017; OECD Publishing: Paris, France; European Observatory on Health Systems and Policies: Brussels, Belgium, 2017. [CrossRef]

25. OECD/European Union. Health at a Glance: Europe 2018: State of Health in the EU Cycle; OECD Publishing: Paris, France, 2018. [CrossRef]

26. Casa Nationala de Asigurari de Sanatate (CNAS). LISTA Cuprinzând Afecţiunile Care Permit Prezentarea Direct la Medicul de Specialitate din Ambulatoriul de Specialitate. (In Romanian). Available online: http://www.cnas.ro/casmb/media/pageFiles/AFECTIUNI\%20CU\%20PREZENTARE\%20DIRECTA\% 20IN\%20AMBULATORIU\%20CLINIC\%2001.04.2018_\%20ANEXA_13\%20.pdf (accessed on 4 April 2020).

27. Federaţia Naţională a Patronatelor Medicilor de Familie (FNPMF). Harta Accesului Cetăţenilor Români la Serviciile de Asistenţă Medicală Primară Oferite de Cabinetele de Medicina Familiei; Federaţia Naţională a Patronatelor Medicilor de Familie (FNPMF): Bucuresti, Romania, 2020. (In Romanian)

28. Pohontsch, N.J.; Hensen, H.; Schafer, I.; Schere, M. General practitioners' perception of being a doctor in urban vs. rural regions in Germany- a focus group study. Fam. Pract. 2018, 35, 209-215. [CrossRef]

29. Nielsen, M.; D'Agostino, D.; Gregory, P. Addressing rural health challenges head on. Mo. Med. 2017, 114, 363-366.

30. Burholt, V.; Naylor, D. The relationship between rural community type and attachment to place for older people living in North Wales, UK. Eur. J. Ageing 2005, 2, 109-119. [CrossRef]

31. Fountain, T.R. Ophthalmic malpractice and physician gender: A claims data analysis (an American ophthalmological society thesis). Trans. Am. Ophtalmol. Soc. 2014, 112, 38-49.

32. Posner, K.L.; Severson, J.; Domino, K.B. The role of informed consent in patient complaints: Reducing hidden health system costs and improving patient engagement through shared decision making. J. Healthc. Risk. Manag. 2015, 35, 38-45. [CrossRef]

33. Fishbain, D.A.; Bruns, D.; Disorbio, J.M.; Lewis, J.E. What are the variables that are associated with the patient's wish to sue his physician in patients with acute and chronic pain? Pain Med. 2008, 9, 1130-1142. [CrossRef] [PubMed]

34. Boyll, P.; Kang, P.; Mahabir, R.; Bernard, R.W. Variables that impact medical malpractice claims involving plastic surgeons in the United States. Aesthet Surg J. 2018, 38, 785-792. [CrossRef] [PubMed]

35. Griffen, F.D.; Stephens, L.S.; Alexander, J.B.; Bailey, R.; Maizel, S.E.; Sutton, B.H.; Posner, K.L. Violations of behavioral practices revealed in closed claims reviews. Ann. Surg. 2008, 248, 118-124. [CrossRef] [PubMed]

36. Hanganu, B.; Manoilescu, I.S.; Velnic, A.A.; Ioan, B.G. Physician-patient communication in chronic diseases. Med. Surg. J. 2018, 122, 417-422.

37. Hanganu, B.; Ioan, B.G. Malpraxisul medical: Cauze şi consecinţe asupra personalului medical. In Psihologie Medicala. Studii Clinice; Iorga, M., Roşca, C., Eds.; Editura Universitară: Bucureşti, Romania, 2019; pp. $183-188$. (In Romanian)

38. Boss, R.D.; Urban, A.; Barnett, M.D.; Arnold, R.M. Neonatal critical care communication (NC3): Training NICU physicians and nurse practitioners. J. Perinatol. 2013, 33, 642-646. [CrossRef]

39. Monden, K.R.; Gentry, L.; Cox, T.R. Delivering bad news to patients. Proc. (Bayl. Univ. Med. Cent.) 2016, 29, 101-102. [CrossRef] [PubMed]

40. Wigert, H.; Blom, M.D.; Bry, K. Parents' experiences of communication with neonatal intensive-care unit staff: An interview with neonatal intensive-care unit staff: An interview study. BMC Pediatr. 2014, 14, 304. [CrossRef] [PubMed] 
41. Agarwal, N.; Gupta, R.; Agarwal, P.; Matthew, P.; Wolfrez, R., Jr.; Shah, A.; Adeeb, N.; Prabhu, A.V.; Kanter, A.; Okonkwo, D.; et al. Descriptive analysis of state and federal spine surgery malpractice litigation in the United States. Spine 2018, 43, 984-990. [CrossRef]

42. Sarin, E.; Maria, A. Acceptability of family-centered newborn care model among providers and receivers of care in a Public Health Setting: A qualitative study from India. BMC Health Serv. Res. 2019, 19, 184. [CrossRef]

43. Lv, B.; Gao, X.; Sun, J.; Li, T.; Liu, Z.; Zhu, L.; Latour, J.M. Family-centered care improves clinical outcomes of very-low-birth-weight infants: A quasi-experimental study. Front. Pediatr. 2019, 7, 138. [CrossRef] [PubMed]

44. Renkema, E.; Broekhuis, M.; Ahaus, K. Conditions that influence the impact of malpractice litigation risk on physicians' behavior regarding patient safety. BMC Health Serv. Res. 2014, 14, 38. [CrossRef]

45. Taghizadeh, Y.; Pourbakhtiar, M.; Ayimi, K.; Ghadipasha, M.; Soltani, K. Claims about medical malpractices resulting in neonatal and maternal impairment in Iran. J. Forensic. Leg. Med. 2019, 66, 44-49. [CrossRef]

46. Gupta, A.; Snyder, A.; Kachalia, A.; Flanders, S.; Saint, S.; Chopra, V. Malpractice claims related to diagnostic errors in the hospital. BMJ Qual. Saf. 2017, 27, 53-60. [CrossRef]

47. Schaffer, A.C.; Jena, A.B.; Seabury, S.A.; Singh, H.; Chalasani, V.; Kachalia, A. Rates and characteristics of paid malpractice claims among US physicians by specialty, 1992-2004. JAMA Int. Med. 2017, 177, 710-718. [CrossRef]

48. Saber Tehrani, A.S.; Lee, H.; Mathews, S.C.; Shore, A.; Makary, M.A.; Pronovost, P.J.; Newman-Toker, D.E. 25-Year summary of US malpractice claims for diagnostic errors 1986-2010: An analysis from the National Practitioner Data Bank. BMJ Qual. Saf. 2013, 22, 672-680. [CrossRef]

49. Zaidi, Z. Gender differences in human brain: A review. Open Anat. J. 2010, 2, 37-55. [CrossRef]

50. Zwaan, L.; de Bruijne, M.; Wagner, C.; Thijs, A.; Smits, M.; van der Wal, G.; Timmermans, D.R.M. Patient record review of the incidence, consequences, and causes of diagnostic adverse events. Arch. Intern. Med. 2010, 170, 1015-1021. [CrossRef] [PubMed]

(C) 2020 by the authors. Licensee MDPI, Basel, Switzerland. This article is an open access article distributed under the terms and conditions of the Creative Commons Attribution (CC BY) license (http://creativecommons.org/licenses/by/4.0/). 